\title{
The Cultivation of College Students' Mechanical Design Innovation
}

\author{
Ability \\ Pin $\mathrm{Lu}$ \\ Xi'an Shi You University, Xi'an 710065, China
}

Keywords: Mechanical design innovation ability

\begin{abstract}
Mechanical design and manufacturing is the basic industry of national economy.Its production level is an important symbol of a country's economic construction. With the innovation and development strategy puting forward, The cultivation of creative design ability about machines of college students' becomes very prominent.Aiming at the shortcomings of the innovation ability training in traditional education, from teaching philosophy, content, method and practice, etc., some measures to cultivate college students' mechanical design innovation ability are put forward.
\end{abstract}

\section{Introduction}

"Innovation, coordination, green, open, sharing" is five big concept of economic development at present in China.The innovation is in the first place.Facing the complex international environment and domestic heavy reform tasks, steady development depend on innovation only. There are quiet a few design and manufacturing technology of China rely on foreign countries. The introduction digestion and absorption of technology, stay in low level of existing technologyand and localization, not to rise to the height of the product independent design. So the enterprise need high quality talents with innovation ability.A mechanical product quality largely depends on the quality of the design which is a creative process. So the mechanical design courses has an irreplaceable role of other courses in students' innovative ability training.

2. The innovation mechanical design ability training of the college students at present

Innovative education in colleges and universities in China started late, began in the late $1990 \mathrm{~s} .2002$ In April, the ministry of education to try innovation education .And innovation education should be brought into the teaching is more late, mechanical innovation education is more after that.In 2004 the first session of mechanical innovation design competition is hold, from then innovative design ability, comprehensive design ability and the cultivation of engineering practice ability is as a mechanical engineering students' training objectives.

3. The theoretical teaching

3.1 Renewing the idea of machine design teaching

Theoretical teaching is the basis of mechanical design teaching. That is at the core position in the whole teaching.In new phase Innovation consciousness and innovation ability is emphasized, but 
don't ignore the basic theory[2].Innovation is a gradual process which need a solid theoretical foundation. Improvement, analogy, simulate and original design is realised on the foundation. The innovation education make the person's mind.The foundation of Innovation is perceptual knowledge, the actual demand of experience and theory.Learning in practice, far more than a simple classroom teaching, effect is remarkable.Sensory input of knowledge and information, hands-on and practical which is a kind of experiential learning.All the senses and neural coordination effect, will greatly improve the learning effect.The main problem is the separation of theory and practicehe in higher education at current.

\subsection{Adding some beneficial contents of the innovation education and curriculum}

Training students' innovative ability do not talk emptly, and should have the creativity techniques. In mechanical design class, innovative thinking and creative techniques should be first introduced. Whether a man has innovation ability depends on whether he had skill training. The method of functions principle design, is very beneficial to cultivate the students' innovation ability in teaching.Subject to time, the chapter about function design is usually left out, but in fact function principle design is a kind of process of innovation conception.In the teaching, the methodshould be throughout the entire teaching .Through living examples, the students understand the general process of the method,Such as a washing machine, its function is to clean the clothes, separate clothes and dirty.If action of hand washing clothes is imitatied, machines will be very complicated.If using the principle of flow friction with clothes, the washing clothes can use simple forward and reverse movement.Using the example of life, students' interest can be stimulated, they will feel innovation near life actually.If total function complex, you can put them into sub-function, functional unit, and then determine the mechanism to realization of each function.It maybe have a variety of solutions, choose the optimal solution.It shows that this method is easy to grasp. A new machine can be to created quickly. The students' innovation ability is improved.

\subsection{Setting up course system of cultivating the ability of innovation}

Traditional mechanical design teaching focuses on the formulas and calculation, complex, key content not prominent. The content of each part is independent of each other and the lack of systematic, practical examples and engineering background.Although all kinds of new technology, new method has been successfully applied in mechanical design field, but the design of the teaching content changed little over the years, and still confined to the traditional design idea and method.To talent training to meet the demand of The Times, mechanical design class must do the following three combination[1].

\subsubsection{The traditional theory and modern design method}

With all kinds of the successful application of advanced technology in the field of mechanical design and manufacturing, mechanical design course content need to correct in time.In addition to the traditional components and parts design method, some advanced design methods should be introduced, such as computer aided design, green design, virtual design, finite element method, etc.At the same time complement parts associated with advanced technology and equipment are added ,such as using a wide range of high temperature bearing, motorized spindle, servo motor, etc., 
to broaden the students' knowledge and develop the students' design ideas.

\subsubsection{Independence combined and systemic}

The whole machine structure design is as the goal. Mechanical component design is the foundation. The relatively independent components are linked to each other, student would have the whole mechanical system design concept.Teaching both pay attention to the independence of the components design relevant knowledge, at the same time, more should emphasize mechanical system design ideas.

\subsubsection{The basic theory and engineering practice}

To achieve the unity of the principles, concepts, methods, applications, which makes the teaching content both scientific and value, students' enthusiasm can be stimulated, It is avoid theory knowledge not contact with actual application easily to feel boring, meeting the and theoretical knowledge.Teachers should not only have a solid foundation for the theory, also need to master professional knowledge, have a certain ability of engineering application.

\section{The Practice}

\subsection{With innovation design ability training as the goal of curriculum series}

the mechanical innovation lecture is opened, Japanese-style mechanical design, SolidEdge 3d-CAD design are opened to form a systematic innovation education for students.Students' comprehensive mechanical design ability is training by use of mechanical design and course design . Students' innovative design and the independently work ability is Cultivated in the teaching. The original design topics is retained in Curriculum design, students are required to give priority to with self-study under the guidance of teachers. Students are encouraged to suspicious of the resources, thinking for structural design. The learning interest and initiative is improved.The mystique of design and innovation is broken by students.

\subsection{Establishing the mechanical innovation design center}

To provide hardware guarantee for students innovation activities, and also the mechanical innovation design center is established, the innovation design experiment and site is provided .Mainly, there are mechanical model, the innovation display and make .

\subsection{To carry out the mechanical design competition}

Desire to stimulate students' innovation and improve the innovative ability of students, The students is organizied to participate in various extracurricular science and technology activities, such as The National Solid Edge Design, Mechanical Innovation Design Competition, The Challenge Cup, Engineering training contest and so on, The students got good grades and apply for patents. 


\subsection{The construction of practical teaching environment}

Starting from the need of cultivating students' innovative ability, mechanical cognitive experiment, properties and innovation experiment is set up[3].Mechanical cognitive experiment mainly through experiment projects, increase understanding and awareness for the student to the motion law, the mechanical structure and types.There are spare parts, mechanical innovation design displayed. Visiting a variety of mechanical parts, simple mechanism and movement process of the actual mechanical,which increase the students' perceptual knowledge, arouse the enthusiasm of students' so that the students had a perceptual knowledge to practical engineering problems.Mechanical performance experiment shows phenomenon, which proves the theory of classroom teaching or law. All kinds of transmission performance comprehensive experiment device is increased in the mechanical properties laboratory.Mechanical innovation design experiment change the passive status of students in the experimental.Designed by the students' experimental project, means, methods, steps show students' innovative thinking and potential.There are drive combination equipment, Lap of mechanism combination equipment, machining equipment, etc., A good experimental environment is provided for the students. Innovation experiment teaching which make students master the basic method to design innovation in practice, improve the students' ability in mechanical design.

\section{Summary}

In mechanical design students innovative ability is cultivated as the goal, by updating the education idea, improving teaching content, to organize extracurricular practice activities means. The teaching system is established on the basis of common institutions and general parts design, the whole machine structure design of mechanical system as emphasis.Pay attention to teaching, experiments and the activities of science and technology and so on. The students' innovatition ability is cultivited.Encourage students to participate in all kinds of positive experiment,to maraster 3-d CAD and extracurricular production, product development and creative thinking. To guide students to participate in The Mechanical Innovation Design Competition and The Challenge Cup Competition by the ministry of education launched, etc. Apply the theoretical knowledge to practice

\section{References}

[1] Li xue-yi, Ding shu-hui ding, Wei jun-ying :Mechanical design course teaching and college students' innovative ability training application,Journal of InnerMongolia Agricultural University(Social Science Edition) No.5 2011(Vol.13 Sum No.59)

[2] Yang yong-zhong, Hu yue-ming :Japan's innovate ability education and its enlightenment, Journal of Chongqing Institute of Technology,12,2000.

[3] Liang feng, Song bao-yu, Liu zhan-shang, Li bai-song:Mechanical Engineering Experimental Teaching and Cultivation of Creative Ability, Research and Explanation in Laboratory, 11, 2006. 